\title{
Effect of $\beta$ blockers on mortality after myocardial infarction in adults with COPD: population based cohort study of UK electronic healthcare records
}

\author{
(c) (1) (8) OPEN ACCESS
}

\author{
J K Quint clinical lecturer in epidemiology ${ }^{1}$, E Herrett research fellow ${ }^{1}$, K Bhaskaran lecturer in \\ statistical epidemiology ${ }^{1}$, A Timmis professor of clinical cardiology ${ }^{2}, \mathrm{H}$ Hemingway professor of \\ epidemiology and public health and director ${ }^{3}$, J A Wedzicha professor of respiratory medicine ${ }^{4}, \mathrm{~L}$ \\ Smeeth professor of clinical epidemiology ${ }^{1}$
}

'Department of Non-Communicable Disease Epidemiology, London School of Hygiene and Tropical Medicine, London WC1E 7HT, UK; ${ }^{2} \mathrm{NIHR}$ Biomedical Research Unit, Barts and the London School of Medicine and Dentistry, London Chest Hospital, London E2 9JX, UK; ${ }^{3}$ Department of Epidemiology and Public Health, and Farr Institute of Health Informatics Research at UCL Partners, University College London, London WC1E 6BT, UK; ${ }^{4}$ Centre for Respiratory Medicine, University College London, Royal Free Campus, London NW3 2PF, UK

\begin{abstract}
Objectives To investigate whether the use and timing of prescription of $\beta$ blockers in patients with chronic obstructive pulmonary disease (COPD) having a first myocardial infarction was associated with survival and to identify factors related to their use.

Design Population based cohort study in England.

Setting UK national registry of myocardial infarction (Myocardial Ischaemia National Audit Project (MINAP)) linked to the General Practice Research Database (GPRD), 2003-11

Participants Patients with COPD with a first myocardial infarction in 1 January 2003 to 31 December 2008 as recorded in MINAP, who had no previous evidence of myocardial infarction in their GPRD or MINAP record. Data were provided by the Cardiovascular Disease Research using Linked Bespoke studies and Electronic Health Records (CALIBER) group at University College London.
\end{abstract}

Main outcome measure Cox proportional hazards ratio for mortality after myocardial infarction in patients with COPD in those prescribed $\beta$ blockers or not, corrected for covariates including age, sex, smoking status, drugs, comorbidities, type of myocardial infarction, and severity of infarct.

Results Among 1063 patients with COPD, treatment with $\beta$ blockers started during the hospital admission for myocardial infarction was associated with substantial survival benefits (fully adjusted hazard ratio $0.50,95 \%$ confidence interval 0.36 to 0.69 ; $\mathrm{P}<0.001$; median follow-up time 2.9 years). Patients already taking a $\beta$ blocker before their myocardial infarction also had a survival benefit $(0.59,0.44$ to 0.79 ;
$P<0.001)$. Similar results were obtained with propensity scores as an alternative method to adjust for differences between those prescribed and not prescribed $\beta$ blockers. With follow-up started from date of discharge from hospital, the effect size was slightly attenuated but there was a similar protective effect of treatment with $\beta$ blockers started during hospital admission for myocardial infarction $(0.64,0.44$ to $0.94 ; \mathrm{P}=0.02)$.

Conclusions The use of $\beta$ blockers started either at the time of hospital admission for myocardial infarction or before a myocardial infarction is associated with improved survival after myocardial infarction in patients with COPD.

Registration NCT01335672.

\section{Introduction}

Patients with chronic obstructive pulmonary disease (COPD) are at increased risk of cardiovascular comorbidities, including myocardial infarction ${ }^{1}$ and have decreased short and long term survival after a myocardial infarction compared with patients without COPD. ${ }^{2-6}$ COPD is currently the fourth leading cause of death in the United States and Europe ${ }^{7}$ and is predicted to become the third by 2020. Up to a third of deaths in patients with COPD are attributable to cardiovascular disease ${ }^{8-11}$ and for every $10 \%$ decrease in forced expiratory volume in one second $\left(\mathrm{FEV}_{1}\right)$, cardiovascular mortality increases by $28 \% .{ }^{8}$ While it is likely that COPD itself contributes to an underlying increase in mortality after myocardial infarction, there could be some potentially modifiable risk factors. 
$\beta$ blockers are effective at reducing risk of mortality and re-infarction after myocardial infarction, ${ }^{12}{ }^{13}$ and they might reduce mortality in patients with COPD with acute coronary syndromes. ${ }^{14}{ }^{15}$ Despite increasing evidence that $\beta$ blockers are safe $^{1617}$ and can actually be beneficial in patients with COPD, even beyond cardiovascular properties, ${ }^{18}$ their use continues to be limited in this group. This is a worldwide phenomenon ${ }^{19}$ and might be related to historical concerns that $\beta$ blockers could be harmful in patients with COPD (for example, by inducing bronchospasm). Such concerns, however, have been challenged by recent evidence. ${ }^{20}$ Cardioselective $\beta$ blockers are less likely to cause bronchospasm, and, additionally, the risk of bronchospasm can be reduced by starting $\beta$ blockers at a lower dose and slowly titrating up.

Using linked Myocardial Ischaemia National Audit Project data (MINAP) and General Practice Research Database (GPRD) data, we aimed to quantify the association between COPD and mortality after myocardial infarction to investigate whether the use and timing of prescription of $\beta$ blockers in patients with COPD after a first myocardial infarction was associated with improved survival, and to identify factors related to the use of $\beta$ blockers in with COPD.

\section{Methods}

\section{Dataset}

For this analysis we used a CALIBER (Cardiovascular disease research using linked bespoke studies and electronic health records) dataset (http://caliberresearch.org.uk/), composed by linkage of data from MINAP and GPRD. MINAP is a national register recording hospital admissions for myocardial infarction and other acute coronary syndromes, with participation from all hospitals in England and Wales that admit patients with these conditions. ${ }^{21}$ GPRD is a large database of research standard anonymised computerised primary care medical records from about five million active patients from around 625 primary care practices throughout the United Kingdom (www.gprd.com). ${ }^{22}$ About half of the practices have consented to linkage, and these practices are based in England.

\section{Study population}

We included patients with COPD experiencing their first myocardial infarction from 1 January 2003 to 31 December 2008 as recorded in MINAP, who had no previous evidence of myocardial infarction in their GPRD or MINAP record. The diagnosis of myocardial infarction was based on the international definition by using discharge diagnosis, results of

electrocardiography results, and markers of myocardial necrosis. Outcomes were assessed between the latest of 1 January 2003, one year after registration with the practice, or one year after the practice quality standards were met for inclusion in GPRD and the earliest of the date of transfer out of the patient, death of the patient, or 31 December 2008. We excluded patients aged under 18, not registered with a GPRD practice during the hospital admission for myocardial infarction, or with less than one year of follow-up before their myocardial infarction. Patients were also excluded if there were inconsistencies regarding patient identifiers between MINAP and GPRD or in timing of the myocardial infarction in MINAP.

We identified COPD in GPRD by using a list of Read codes derived from previously published literature (appendix). ${ }^{23}$ The COPD code list was applied such that patients were defined as having COPD if they had a recorded diagnosis of COPD before or after myocardial infarction. This was done as patients might not be diagnosed with COPD until they have symptoms, at which point they usually have GOLD stage III or IV disease. As such they will have had COPD for some time before their diagnosis. In a sensitivity analysis, however, we redefined individuals' COPD status based only on the presence or absence of a COPD diagnosis before their myocardial infarction. We developed and used a code list for exacerbations of COPD (appendix) within the patients with COPD to identify exacerbations. We classified patients as having an exacerbation if the patient had an exacerbation code and was prescribed a predefined antibiotic or oral prednisolone, or both. We chose this method to maximise the likelihood of an exacerbation truly being an exacerbation, but this could have led to an underestimation of the true number of exacerbations experienced. As treatment was included in the definition of exacerbation, the presence of two or more exacerbations a year was defined as frequent exacerbations. ${ }^{24}$

Information on COPD (including disease severity by GOLD staging and MRC score), demographic factors (age in approximate quarters, sex, ethnicity), previous cardiovascular disease (angina, heart failure), cardiovascular risk factors (hypertension, diabetes, dyslipidaemia, family history, smoking history (current, former, or never), peripheral arterial disease, cerebrovascular disease), and drug prescriptions (aspirin, statins, angiotensin converting enzyme inhibitors, $\beta$ blockers, and drugs for COPD) were obtained from GPRD. In addition, MINAP data provided information on results of electrocardiography at the time of presentation, type of myocardial infarction, markers of severity of infarct (peak troponin concentrations), smoking status at admission, drugs given on admission, and drugs on discharge, including prescription of $\beta$ blockers. Cut points for hypertension reflected National Institute for Health and Clinical Excellence (NICE) guidelines. ${ }^{22}$

The use of $\beta$ blockers during the hospital admission for myocardial infarction was obtained from MINAP only. The $\beta$ blocker variable in MINAP used to identify whether or not patients were prescribed a $\beta$ blocker during the hospital admission for myocardial infarction was coded as "yes" if a $\beta$ blocker was continued from before admission or newly started during the hospital admission for myocardial infarction and continued at the time of discharge from hospital. Patients not prescribed a $\beta$ blocker at myocardial infarction were coded as "no." Other coding options included in this variable were $\beta$ blocker contraindicated, not applicable, not indicated, or missing. These individuals were never included in the dataset so that we did not introduce misclassification (fig $1 \Downarrow$ ).

The MINAP variable used to ascertain $\beta$ blocker use was coded such that the $\beta$ blocker could have been started at any point from the day of admission for the myocardial infarction and was then continued on discharge. We assumed that $\beta$ blockers would be started as soon as possible after admission for myocardial infarction and therefore took the day of myocardial infarction as the start date of $\beta$ blocker use. No information from after discharge fed into the classification of patients into the three $\beta$ blocker groups. We used information from GPRD to ascertain $\beta$ blocker use before the myocardial infarction and long term use afterwards. The date of the last prescription in GPRD was used to determine length of treatment. Median duration of use was calculated based on prescription length. Patients were not required to have two prescriptions to be included in the $\beta$ blocker exposed group as this would have introduced an immortal time bias. Immortal time bias can occur when determination of treatment status for an individual involves a delay in which follow-up time is still accrued. No patient had only one prescription on the day of myocardial infarction. 


\section{Primary outcome}

The primary outcome was all cause mortality after a first ST elevation (STEMI) or non-ST elevation myocardial infarction (NSTEMI) in patients with COPD prescribed and not prescribed a $\beta$ blocker during the hospital admission for myocardial infarction. Information on death was based on data from Office for National Statistics death certificates. Cause specific mortality, broken down into cardiac and non-cardiac causes based on ICD-10 (international classification of diseases, 10th revision) codes from death certificate data, was investigated in a secondary analysis. We also investigated short term (one year) all cause mortality in a sensitivity analysis.

\section{Analyses}

We used $\chi^{2}$ tests to compare demographic factors, the prevalence of risk factors before myocardial infarction, and drugs and management at the time of and after myocardial infarction in patients with COPD prescribed or not prescribed $\beta$ blockers during the hospital admission for myocardial infarction. Crude mortality rates were calculated. We analysed time from myocardial infarction (that is, the date of the myocardial infarction) to death using Cox proportional hazards models to produce adjusted hazard ratios to determine whether mortality differed between those prescribed and not prescribed a $\beta$ blocker during the hospital admission for myocardial infarction. To investigate the effect of timing of prescription of $\beta$ blockers, we divided people into those with no evidence of $\beta$ blocker prescription over the study period, those who had been prescribed $\beta$ blockers before their myocardial infarction, and those prescribed $\beta$ blockers for the first time in the immediate aftermath of their myocardial infarction (during their hospital admission). Smoking status, age, and sex were included in all models as they were deemed a priori to be probable confounders. We then added all measured confounders cumulatively to the model in a model building table. These included age, sex, smoking, the presence of family history of cardiovascular disease, angina, hypertension, dyslipidaemia, peripheral arterial disease, cerebrovascular disease, heart failure and diabetes before myocardial infarction, frequency of exacerbations of COPD, type of myocardial infarction, and drug use at the time of or before myocardial infarction (diuretics, anti-arrhythmia drugs, antiplatelet agents, angiotensin converting enzyme inhibitor, statins, nitrates, and calcium channel blockers). Data were managed and the analysed with STATA 11.

To investigate the duration of $\beta$ blocker use from the time of myocardial infarction, we analysed these data using time to event Kaplan Meier methods for time to stopping. We defined stopping as the date of the last prescription plus the median length of time between prescriptions.

\section{Sensitivity analyses and propensity scores}

Sensitivity analyses were performed to explore possible effects of misclassification with respect to the timing of the diagnosis of COPD by repeating the analysis including only those with a diagnosis made before their myocardial infarction. ${ }^{25}$ Propensity scores (the propensity for being prescribed a $\beta$ blocker during the hospital admission for myocardial infarction) were used as an alternative way of adjusting for differences in groups of patients with COPD prescribed and not prescribed a $\beta$ blocker. We included in the propensity score all covariates included in the model building table and obtained a final hazard ratio adjusted for propensity score. This allowed us to determine whether patients prescribed and not prescribed a $\beta$ blocker were truly comparable. The covariates that contributed to the final propensity score hazard ratio included age; sex; smoking; a family history of cardiovascular disease, angina, hypertension, dyslipidaemia, peripheral arterial disease, cerebrovascular disease, heart failure, and diabetes before myocardial infarction; frequency of exacerbations; type of myocardial infarction; and drug use at the time of or before myocardial infarction, including diuretics, anti-arrhythmia drugs, antiplatelet agents, angiotensin converting enzyme inhibitor, statins, nitrates, and calcium channel blockers. Propensity scores were calculated with STATA and adjusted for as a categorical variable in the analysis (using logistic regression with death as the outcome) to give a final ratio. In a sensitivity analysis we also included GOLD staging and infarct severity (peak troponin concentrations) in the model. We did not include GOLD staging or infarct severity in the main analysis as data were not available in all patients. We also undertook further sensitivity analyses matching on propensity scores (1:1 matching, each exposed patient was matched to an unexposed patient whose propensity score was within $+/-0.01)$. We re-ran the analysis using the date of admission plus one day and date of discharge from hospital as start time for follow-up (that is, excluding some/all individuals who died in hospital) as we did not know the exact timing of starting the $\beta$ blocker in hospital but had assumed it to be the same date as the myocardial infarction for the main analysis.

\section{Results}

Of the 2209 patients with COPD identified in MINAP with a first myocardial infarction with the inclusion and exclusion criteria applied, $1146(51.8 \%)$ were excluded as $\beta$ blockers were not coded yes/no. In 679 (59.2\%) $\beta$ blockers were coded as being contraindicated, but we do not have details on why. We included 1063 patients in the analysis (fig $1 \Downarrow$ ). Patients with COPD prescribed a $\beta$ blocker during the hospital admission for myocardial infarction were younger and less likely to have a history of hypertension, cerebrovascular disease, peripheral arterial disease, heart failure, dyslipidaemia, or angina before their myocardial infarction. They were also more likely to have infrequent exacerbations and less likely to have been prescribed diuretics before the myocardial infarction (table $1 \Downarrow$ ).

Data on $\mathrm{FEV}_{1}$ and height were available in 600 patients (56\%), allowing us to calculate $\mathrm{FEV}_{1} \%$ predicted and GOLD staging in this group. GOLD staging was similar in those prescribed and not prescribed a $\beta$ blocker. Table 2 provides information on COPD drugs and cardiac drugs prescribed before the myocardial infarction $\Downarrow$. Table 3 shows other cardiac drugs prescribed during the hospital admission for myocardial infarction. $\Downarrow$

The $\beta$ blockers prescribed during the hospital admission for myocardial infarction were predominantly cardioselective, and data were available on $193(82.8 \%)$ of patients. Bisolprolol was most commonly prescribed $(111,57.5 \%)$, followed by atenolol $(48,24.9 \%)$, metoprolol $(22,11.4 \%)$, carvedilol $(7,3.6 \%)$, nebivolol $(2,1.0 \%)$, propranolol $(2,1 \%)$, and sotalol $(1,0.5 \%)$.

\section{Survival analysis}

The median length of follow-up after myocardial infarction was 2.9 years (range 0.09-7.2 years). After adjustment for history of smoking and sex and stratification by age, patients with COPD prescribed a $\beta$ blocker during the hospital admission for myocardial infarction and those prescribed a $\beta$ blocker before the myocardial infarction had better survival than those never prescribed a $\beta$ blocker: hazard 0.45 (95\% confidence interval 0.34 to $0.60, \mathrm{P}<0.001)$ and 0.72 (0.57 to $0.90, \mathrm{P}=0.004)$, respectively (fig $2 \Downarrow$ ). 
With respect to prescription of a $\beta$ blocker during the hospital admission for myocardial infarction, the addition of covariates to the model did not significantly alter the hazard ratio (table $4 \Downarrow$; fully adjusted hazard ratio $0.50,95 \%$ confidence interval 0.36 to $0.69 ; \mathrm{P}<0.001$ ). With adjustment for all covariates there was also a survival benefit in patients prescribed a $\beta$ blocker before myocardial infarction compared with those never prescribed a $\beta$ blocker $(0.59,0.44$ to $0.79 ; \mathrm{P}<0.001)$.

With adjustment for all covariates and one year survival as the outcome, there was a short term survival benefit in patients prescribed a $\beta$ blocker during the hospital admission for myocardial infarction compared with those never prescribed a $\beta$ blocker (fully adjusted hazard ratio $0.48,95 \%$ confidence interval 0.30 to $0.76 ; \mathrm{P}=0.002$ ). There was also a short term survival benefit in patients already taking a $\beta$ blocker before myocardial infarction compared with those never prescribed a $\beta$ blocker $(0.68,0.46$ to $1.0 ; \mathrm{P}=0.05)$.

\section{Causes of death}

Cardiac and non-cardiac deaths were similar in patients with COPD prescribed and not prescribed a $\beta$ blocker during the hospital admission for myocardial infarction (49\% and 51\%, respectively; table $5 \Downarrow$ ). After adjustment for age, sex, history of smoking, and frequency of exacerbations, survival analysis with cardiac and non-cardiac death as the outcome showed an improved survival in those prescribed a $\beta$ blocker compared with those not prescribed a $\beta$ blocker during the hospital admission for myocardial infarction (hazard ratio for cardiac deaths 0.57 (95\% confidence interval 0.38 to $0.86 ; \mathrm{P}=0.03$ ) and non-cardiac deaths $0.49(0.32$ to $0.75 ; \mathrm{P}=0.01)$, respectively.

\section{Sensitivity analyses and propensity scores}

We undertook several sensitivity analyses (table $6 \Downarrow$ ), including matching on propensity score and using propensity score as a variable in the Cox proportional hazards model, using all covariates included in the previous model (see table 4). When we repeated the analysis splitting patients into only two group - those taking $\beta$ blockers or not at discharge from hospital for myocardial infarction irrespective of previous use- the results were not significantly different. Adjustment for possible variation in start date of $\beta$ blockers during the hospital admission for myocardial infarction did not significantly alter the outcome. When we started follow-up from day of admission plus one day or from date of discharge from hospital, the effect size was slightly attenuated, but we observed a similar protective effect of $\beta$ blockers initiated during hospital admission for myocardial infarction.

\section{Prescriptions and tolerability of $\beta$ blockers after myocardial infarction}

Of patients with COPD who died in hospital, 15.2\% (10/66) were prescribed a $\beta$ blocker compared with $22.4 \%$ (223/997) of those who survived their hospital admission. Of those prescribed a $\beta$ blocker during the hospital admission for myocardial infarction, $203(87.1 \%)$ were still taking a $\beta$ blocker at six months, $185(79.4 \%)$ were still receiving prescriptions for a $\beta$ blocker at one year, and $142(60.9 \%)$ at two years. The median time to stopping $\beta$ blockers was 3.5 years. All patients prescribed a $\beta$ blocker during the hospital admission for myocardial infarction had subsequent prescriptions from their general practitioner. Of the 244 patients taking a $\beta$ blocker before the myocardial infarction, 87 (35.7\%) had the $\beta$ blocker stopped on admission. A total of $38.6 \%$ of the study population started taking a $\beta$ blocker at myocardial infarction or continued taking a $\beta$ blocker that they were already taking. We do not have any data to suggest that $\beta$ blockers were used in preference to calcium channel blockers.

\section{Discussion \\ Principal findings}

In this large population based study we showed that among people with COPD, use of a $\beta$ blocker after a first myocardial infarction was associated with lower subsequent mortality. Only $38.6 \%$ of people with COPD, however, received a $\beta$ blocker during the hospital admission for myocardial infarction. This is the first study to use linked detailed hospital data on myocardial infarction to the longitudinal clinical records from primary care to assess mortality after myocardial infarction among people with COPD. It is also the largest study to date of the effect of $\beta$ blockers on survival after myocardial infarction among patients with COPD. ${ }^{2-6}$ One of the advantages of this study is the use of MINAP data, which clearly defines first myocardial infarction and provides detailed information on management at the time of the event as well as type and severity of infarct.

Patients with COPD who were prescribed $\beta$ blockers were younger and had less cardiovascular comorbidity and fewer exacerbations, and, with adjustment for these issues in the analysis, we found that $\beta$ blockers still improved survival when they were prescribed during the hospital admission for myocardial infarction. Survival after myocardial infarction was longest in those with COPD who started taking $\beta$ blockers during the hospital admission for myocardial infarction compared with those already taking them or never prescribed them. Patients not prescribed $\beta$ blockers during the hospital admission for myocardial infarction were more likely to be taking inhalers for their COPD and might have been more likely to have symptoms from their COPD. Patients with COPD prescribed $\beta$ blockers during the hospital admission for myocardial infarction are at a higher risk of death having just had a myocardial infarction and this might be why they are more effective in this group. Those prescribed $\beta$ blockers before myocardial infarction might have been given $\beta$ blockers for reasons other than ischaemic heart disease and thus be a more heterogeneous group.

\section{Comparison with other studies}

A 1998 study by Gottlieb and colleagues suggested that the prescription of $\beta$ blockers after myocardial infarction in patients with COPD improved survival. ${ }^{12}$ Even now, however, we found that $\beta$ blockers are not prescribed often after myocardial infarction in such patients, regardless of the type of myocardial infarction. Tolerability did not seem to be a problem for patients with COPD, with a median length of prescription 3.5 years after myocardial infarction. The reluctance to prescribe $\beta$ blockers after myocardial infarction in these patients is a worldwide phenomenon but seems to have diminished as an issue outside the UK. A recent study based in the US found that discrepancies in treatment after myocardial infarction between those with and without COPD has narrowed in recent years, with $\beta$ blockers prescribed in over $90 \%$ of both groups by $2007 .{ }^{19}$

We found that the decrease in mortality in those patients with COPD prescribed a $\beta$ blocker at myocardial infarction was due to a reduction in both cardiac and non-cardiac deaths. There have been suggestions that the benefit of $\beta$ blockers in these patients might go beyond cardiac effects, and this could explain the reduction in non-cardiac deaths. ${ }^{16}{ }^{17}$ NICE guidelines on heart failure now specifically include patients with COPD,${ }^{18}$ but we found that they remain underprescribed in this group. $\beta$ 
blockers seem to be safe and well tolerated based on these observational data. Cardioselective $\beta$ blockers were predominantly used in this group and are less likely to cause bronchospasm. There is evidence that $\beta$ blockers do not detrimentally affect lung function in patients with COPD $^{16} 17$ and thus severity of disease or the lack of spirometry at the time of hospital admission for myocardial infarction should not deter their prescription. In COPD airways disease is usually poorly reversible and $\beta$ blockers should not induce bronchospasm.

Though a randomised controlled trial of $\beta$ blockers in patients with COPD could examine some of the perceived safety concerns that remain around their prescription, there is sufficient evidence to suggest it would be unethical to withhold $\beta$ blockers after myocardial infarction in patients with COPD and perform a trial of this nature. In addition to increasing evidence of safety, ${ }^{26}{ }^{27}$ there is evidence that they reduce exacerbations and mortality independent of cardiovascular risk in those with COPD. $^{28}$

Patients with frequent exacerbations have more symptoms and more dyspnoea than those with infrequent exacerbations. ${ }^{29}$ Physicians might be worried about breathlessness associated with exacerbations and do not prescribe $\beta$ blockers in this group. Those with frequent exacerbations are at risk of cardiovascular disease and are more likely to have cardiovascular comorbidity than those with infrequent exacerbations. ${ }^{30}$ Perhaps we should be more definite about prescribing $\beta$ blockers in this group.

\section{Strengths and limitations}

Myocardial infarction was defined with rigorous criteria according to the international definition, and one of the strengths of this study is the detailed information provided in MINAP surrounding the diagnosis and management at the time of a myocardial infarction, including information on the prescription of $\beta$ blockers, type of myocardial infarction, and severity of the infarct (troponin concentrations). We combined information from GPRD and MINAP and were able to adjust for a wide range of possible confounders. Another advantage was the detailed information available on comorbidities and drug prescriptions both before and after the myocardial infarction. We used a stringent code list to diagnose COPD and exacerbations. This approach might have led to an underestimation of the true number of patients with COPD and exacerbations in this cohort and therefore an underestimation of the real survival difference. Prescription records could not be used to improve the sensitivity of diagnosis of COPD as there is overlap in the use of drugs for treatment of other respiratory diseases. Reassuringly, our observed prevalence of COPD was similar to that from other studies. ${ }^{1-31}$ The inclusion of COPD diagnosis made after the myocardial infarction as well as before could have reduced misclassification, and sensitivity analyses confirmed this did not introduce an immortal time bias. ${ }^{32}$ Most diagnoses of COPD were made before or around the time of the myocardial infarction. The dataset was large, and the overall percentage of missing data acceptable and small compared with other methods of data collection.

One of the limitations of this study was the coding of $\beta$ blocker use during the hospital admission for myocardial infarction in MINAP. Patients were more likely to be coded as not being prescribed a $\beta$ blocker if they died in hospital. Repeated analysis with date of discharge from hospital as the start time of follow-up, however, confirmed that $\beta$ blockers do have a protective effect. One of the reasons for the differences in the effect size comparing start of follow-up from date of myocardial infarction and start of follow-up at discharge from hospital could be a potential immortal time bias as patients had to have $\beta$ blockers use coded as yes or no to be included in the study, and to have $\beta$ blocker use coded, patients were more likely to have survived the hospital stay. Nonetheless, the overall protective effect of $\beta$ blockers was still preserved with change of the start of follow-up time.

Another limitation of this study is the possible survival bias that occurs with using MINAP. To be included, patients must have survived long enough to be admitted to hospital and possibly even a coronary care unit. Patients with COPD might be less likely to survive an initial event and might be less likely to be included in MINAP if their myocardial infarction is slow to be diagnosed or misclassified as an exacerbation and they are admitted to a general hospital ward. Though general practices are self selecting with respect to their contribution to GPRD, they seem to be representative of the UK population. ${ }^{33}$ Few patients within contributing practices refuse to participate at an individual level, and this is not thought to bias the results. There were hidden missing variables in GPRD that meant that if data were missing, they were classified as not present. We were able to assess the effect of COPD disease severity using only GOLD staging in a subset of patients. We were also not able to confirm that the reason for not starting treatment with a $\beta$ blocker during the hospital admission for myocardial infarction in the patients with COPD really was because the patient had COPD. We cannot be sure that when $\beta$ blockers were stopped this was because of poor tolerability. Though efforts were made to control for confounding, there might be some residual confounding (such as unmeasured comorbidities). One of the difficulties with observational studies is that there could be residual bias and confounding by contraindication. There is also the risk of healthy user bias in those patients who take any drug treatment, including $\beta$ blockers. While the effect in reality might not be as large as observed in this study, some protective effect seems likely, and, in view of these findings, it is difficult to believe that the effect of $\beta$ blockers is harmful.

Of patients with COPD excluded from the study, nearly $60 \%$ (679) were not prescribed a $\beta$ blocker during the hospital admission for myocardial infarction as the drug was contraindicated. We do not have any further information on why the clinician treating the patient thought that $\beta$ blockers were contraindicated. While it is possible that some physicians could have thought that having a diagnosis of COPD was a contraindication, potentially allowing us to include those individuals in the analysis, we could not determine this and so they were excluded. This might have led to a selection bias in our COPD sample. We did not have information on comorbidities such as atrial fibrillation, which might also be a reason for $\beta$ blockers to be prescribed. We were not able to assess the effect in patients with severe COPD who were receiving long term oxygen therapy.

\section{Conclusions and policy implications}

The use of $\beta$ blockers before and at the time of a myocardial infarction was associated with improved survival in patients with COPD. Use of $\beta$ blockers remains limited in patients with COPD, and this lack of prescribing might be contributing to the increase in mortality in these patients after myocardial infarction. Our data suggest that $\beta$ blockers should be used more widely in patients with COPD who have had a myocardial infarction. Safety to date is good in these patients, but further evaluation of the safety of $\beta$ blockers in this high risk group might be required to change current prescribing practice. 


\section{What is already known on this topic}

Use of $\beta$ blockers is associated with reduced mortality after myocardial infarction in the general population

Despite increasing evidence that $\beta$ blockers are safe and might actually be beneficial in patients with COPD irrespective of myocardial infarction, they continue to be underprescribed after myocardial infarction in this group

\section{What this study adds}

We used detailed data during the hospital admission for myocardial infarction available from MINAP, including type and severity of myocardial infarction, to investigate $\beta$ blocker prescription in patients with COPD linked with longitudinal health care records (GRPD) with adjustment for co-morbidities and other confounders

$\beta$ blockers are not widely used in patients with COPD who have had a myocardial infarction and could be more widely used Use of $\beta$ blockers started either at the time of hospital admission for myocardial infarction or before a myocardial infarction was associated with improved survival after myocardial infarction in patients with COPD

Contributors: JKQ, AT, HH, JAW, and LS contributed to the conception and design, JKQ, EH, and $\mathrm{KB}$ acquired, analysed, and interpreted data. All authors drafted the manuscript. JKQ is guarantor.

Funding: This research received no specific grant from any funding agency in the public, commercial, or not-for-profit sectors.

Competing interests: All authors have completed the Unified Competing Interest form at www.icmje.org/coi_disclosure.pdf (available on request from the corresponding author) and declare: no support from any organisation for the submitted work; no financial relationships with any organisations that might have an interest in the submitted work in the previous three years, no other relationships or activities that could appear to have influenced the submitted work. JKQ is funded by the Medical Research Council, UK, LS is funded by The Wellcome Trust, KB is funded by a National Institute for Health Research postdoctoral fellowship (PDF-2011-04-007). AT acknowledges support of BartsHealth Cardiovascular Biomedical Research Unit, funded by the National Institute for Health Research. CALIBER is supported by grants from the UK National Institute for Health Research (grant No RP-PG-0407-10314) and the Wellcome Trust $(086091 / \mathrm{Z} / 08 / \mathrm{Z})$. HH is supported by grants from the UK National Institute for Health Research (RP-PG-0407-10314) and the Wellcome Trust [086091/Z/08/Z], and by awards establishing the Farr Institute of Health Informatics Research at UCL Partners from the MRC, in partnership with Arthritis Research UK, the British Heart Foundation, Cancer Research UK, the Economic and Social Research Council, the Engineering and Physical Sciences Research Council, the National Institute of Health Research, the National Institute for Social Care and Health Research (Welsh Assembly Government), the Chief Scientist Office (Scottish Government Health Directorates) and the Wellcome Trust. The views and opinions expressed therein are those of the authors and do not necessarily reflect those of the NIHR PHR Programme or the Department of Health.

Ethical approval: The study was approved by ISAC (the Independent Scientific Advisory Committee overseeing GPRD), MAG (MINAP Academic Group), the LSHTM ethics committee, and CALIBER. The primary outcome from the initial ISAC protocol has been previously published. $^{34}$

Transparency declaration: The lead author affirms that this manuscript is an honest, accurate and transparent account of the study being reported and that no aspects have been omitted.

Data sharing: No additional data available.

1 Feary JR, Rodrigues LC, Smith CJ, Hubbard RB, Gibson JE. Prevalence of major comorbidities in subjects with COPD and incidence of myocardial infarction and stroke: a comprehensive analysis using data from primary care. Thorax 2010;65:956-62.

2 Wakabayashi K Gonzalez MA, Delhaye C, Ben-Dor I, Maluenda G, Collins SD, et al. Impact of chronic obstructive pulmonary disease on acute-phase outcome of myocardial infarction. Am J Cardiol 2010;106:305-9.

3 Bursi F, Vassallo R, Weston SA, Killian JM, Roger VL. Chronic obstructive pulmonary disease after myocardial infarction in the community. Am Heart J 2010;160:95-101.

4 Salisbury AC. Reid KJ. Spertus JA. Impact of chronic obstructive pulmonary disease on post-myocardial infarction outcomes. Am J Cardiol 2007:99:636-41.

5 Kjoller E, Kober L, Iversen K, Torp-Pedersen C. Trace Study Group. Importance of chronic obstructive pulmonary disease for prognosis and diagnosis of congestive heart failure in patients with acute myocardial infarction. Eur J Heart Failure 2004;6:71-7.
6 Huiart L, Ernst P, Ranouil X, Suissa S. Oral corticosteroid use and the risk of acute myocardial infarction in chronic obstructive pulmonary disease. Can Respir $\mathrm{J}$ 2006;13:134-8.

7 Global Initiative for Chronic Obstructive Lung Disease. Global Strategy for the diagnosis, management and prevention of chronic obstructive pulmonary disease. (GOLD) 2006, updated 2010. www.goldcopd.org.

8 Anthonisen NR, Connett JE, Murray RP. Smoking and Lung Function of Lung Health Study Participants after 11 years. Am J Respir Crit Care Med 2002;166:675-9.

9 Sin DD, Anthonisen NR, Soriano JB, Agusti AG. Mortality in COPD: role of comorbidities. Eur Respir J 2006;28:1245-57.

10 Calverley PMA, Anderson JA, Celli B, Ferguson GT, Jenkins C, Jones PW, et al, for the TORCH investigators. Salmeterol and fluticasone propionate and survival in chronic obstructive pulmonary disease. N Engl J Med 2007;356:775-89.

11 Schneider C, Bothner U, Jick SS, Meier CR. Chronic obstructive pulmonary disease and the risk of cardiovascular diseases. Eur J Epidemiol 2010;25:253-60.

12 Gottlieb SS, McCarter RJ, Vogel RA. Effect of beta-blockade on mortality among high-risk and low-risk patients after myocardial infarction. N Engl J Med 1998;339:489-97.

13 National Collaborating Centre for Primary Care, 2007. Post myocardial infarction: secondary prevention in primary and secondary care for patients following a myocardial infarction. www. nice.org.uk/CG048.

14 Olenchock BA, Fonarow GG, Pan W, Hernandez A, Cannon CP; Get With The Guidelines Steering Committee. Current use of $\beta$ blockers in patients with reactive airway disease who are hospitalized with acute coronary syndromes. Am J Cardiol 2009;103:295-300.

15 Chen J, Radford MJ, Wang Y, Marciniak TA, Krumholz HM. Effectiveness of $\beta$-blocke therapy after acute myocardial infarction in elderly patients with chronic obstructive pulmonary disease or asthma. J Am Coll Cardiol 2001;37:1950-6.

16 Dransfield MT, Rowe SM, Johnson JE, Bailey WC, Gerald LB. Use of beta blockers and the risk of death in hospitalised patients with acute exacerbations of COPD. Thorax 2008:63:301-5.

17 Short PM, Lipworth SI, Elder D, Schembri S, Lipworth BJ. Effect of $\beta$ blockers in treatment of chronic obstructive pulmonary disease: a retrospective cohort study. BMJ 2011;342:d2549.

18 National Clinical Guidelines Centre, 2010. Chronic heart failure: national clinical guideline for diagnosis and management in primary care. August 2010.www.nice.org.uk/nicemedia/ live/13099/50514/50514.pdf.

19 Stefan MS, Bannuru RR, Lessard D, Gore JM, Lindenauer PK, Goldberg RJ. The impac of COPD on management and outcomes of patients hospitalized with acute myocardial infarction: a 10-year retrospective observational study. Chest 2012;141:1441-8.

20 Albouaini K, Andron M, Alahmar A, Egred M. Beta-blockers use in patients with chronic obstructive pulmonary disease and concomitant cardiovascular conditions. Int J Chron Obstruct Pulmon Dis 2007:2:535-40.

21 Herrett E, Smeeth L, Walker L, Weston C; MINAP Academic Group. The myocardial ischaemia national audit project (MINAP). Heart 2010;96:1264-7.

22 Hypertension. Clinical management of primary hypertension in adults. NICE Guideline 34, updated August 2011. www.nice.org.uk/nicemedia/live/13561/56008/56008.pdf.

23 Donaldson GC, Hurst JR, Smith CJ, Hubbard RB, Wedzicha JA. Increased risk of myocardial infarction and stroke following exacerbation of COPD. Chest 2010;137:1091-7.

24 Hurst JR, Vestbo J, Anzueto A, Locantore N, Müllerova $\mathrm{H}$, Tal-Singer $\mathrm{R}$, et al, for the Evaluation of COPD Longitudinally to Identify Predictive Surrogate Endpoints (ECLIPSE) Investigators. Susceptibility to exacerbation in chronic obstructive pulmonary disease. $N$ Engl J Med 2010;363:1128-38

25 Sturmer T, Joshi M, Glynn RJ, Avorn J, Rothman KJ, Schneeweiss S. A review of the application of propensity score methods yielded increasing use, advantages in specific settings, but not substantially different estimates compared with conventional multivariable methods. J Clin Epidemiol 2006:59:437-47.

26 Salpeter SR, Ormiston TM, Salpeter EE. Cardioselective beta-blockers for chronic obstructive pulmonary disease. Cochrane Database Syst Rev 2005;4:CD003566.

27 Can beta-blockers be used for people with COPD? Drug Ther Bull 2011;49: 2-5.

28 Rutten FH, Zuithoff NP, Hak E, Grobbee DE, Hoes AW. Beta-blockers may reduce mortality and risk of exacerbations in patients with chronic obstructive pulmonary disease. Arch Intern Med 2010 24:170:880-7.

29 Donaldson GC, Seemungal TAR, Bhowmik A, Wedzicha JA. Relationship between exacerbation frequency and lung function decline in chronic obstructive pulmonary disease. Thorax 2002;57:847-52.

30 Niewoehner DE, Lokhnygina Y, Rice K, Kuschner WG, Sharafkhaneh A, Sarosi GA, Krumpe P, Pieper K, Kesten S. Risk indexes for exacerbations and hospitalizations due to COPD Chest $2007 \cdot 131 \cdot 20-8$

31 Bursi F, Vassallo R, Weston SA, Killian JM, Roger VL. Chronic obstructive pulmonary disease after myocardial infarction in the community. Am Heart J 2010;160:95-101.

32 Suissa S. Effectiveness of inhaled corticosteroids in chronic obstructive pulmonary disease: immortal time bias in observational studies. Am J Respir Crit Care Med 2003:168:49-53.

33 Parkinson JP, Davis S, Van Staa T. The General Practice Research Database: now and the future. In: Mann R, Andrews EB, eds. Pharmacovigilance. John Wiley, 2007:341-8. 
34 Quint JK, Herrett E, Timmis A, Hemingway H, Smeeth L. Survival after the first myocardial infarction is shorter in patients with COPD compared to the general population. Thorax 2011:66(suppl 4):A45-46.

Accepted: 25 October 2013

Cite this as: BMJ 2013;347:f6650
Published by the BMJ Publishing Group Limited. For permission to use (where not already granted under a licence) please go to http://group.bmj.com/group/rights-licensing/ permissions

This is an Open Access article distributed in accordance with the Creative Commons Attribution (CC BY 4.0) license, which permits others to distribute, remix, adapt and build upon this work, for commercial use, provided the original work is properly cited. See: http: //creativecommons.org/licenses/by/4.0/ . 


\section{Tables}

Table 1| Characteristics of 1063 patients with chronic obstructive pulmonary disease (COPD) and timing of $\beta$ blocker prescription relative to myocardial infarction. Figures are numbers (percentage) of patients according to use of $\beta$ blockers

\begin{tabular}{|c|c|c|c|c|}
\hline Category & Total & $\begin{array}{l}\text { Never took } \beta \text { blocker }(n=586 \text {, } \\
\text { (55.1\%) }\end{array}$ & $\begin{array}{c}\text { Took } \beta \text { blocker before myocardial } \\
\text { infarction }(n=244,23.0 \%)\end{array}$ & $\begin{array}{c}\text { Prescribed } \beta \text { blocker only at } \\
\text { myocardial infarction }(n=233 \text {, } \\
21.9 \%)\end{array}$ \\
\hline Men & $651(61.2)$ & $354(60.4)$ & $138(56.6)$ & $159(68.2)$ \\
\hline Women & $412(38.8)$ & $232(39.6)$ & $106(43.4)$ & $74(31.8)$ \\
\hline \multicolumn{5}{|l|}{ Age (years): } \\
\hline$<60$ & $137(12.9)$ & $69(11.8)$ & $25(10.3)$ & $43(18.5)$ \\
\hline $61-70$ & $305(28.7)$ & $160(27.3)$ & $71(29.1)$ & $74(31.8)$ \\
\hline $71-80$ & $351(33.0)$ & $201(34.3)$ & $78(32.0)$ & $72(30.9)$ \\
\hline$>80$ & $270(25.4)$ & $156(26.2)$ & $70(28.7)$ & $44(18.9)$ \\
\hline $\begin{array}{l}\text { Family history of cardiovascular } \\
\text { disease }\end{array}$ & $245(23.1)$ & $133(22.7)$ & $55(22.5)$ & $57(24.5)$ \\
\hline \multicolumn{5}{|l|}{ Smoking status $(n=1060)$ : } \\
\hline Non-smoker & $57(5.4)$ & $31(5.3)$ & $16(6.6)$ & $10(4.3)$ \\
\hline Ex-smoker & $610(57.4)$ & $345(58.9)$ & $142(58.2)$ & $123(52.8)$ \\
\hline Current & $393(37.0)$ & $207(35.3)$ & $86(35.3)$ & $100(42.9)$ \\
\hline Previous history of angina & $327(30.8)$ & $175(29.9)$ & $106(43.4)$ & $46(19.7)$ \\
\hline Hypertension & $551(51.8)$ & $280(47.8)$ & $174(71.3)$ & $97(41.6)$ \\
\hline Dyslipidaemia & $166(15.6)$ & $95(16.2)$ & $52(21.3)$ & $19(8.2)$ \\
\hline Peripheral arterial disease & $156(14.7)$ & $92(15.7)$ & $42(17.2)$ & $22(9.4)$ \\
\hline Previous cerebrovascular disease & $139(13.1)$ & $85(14.5)$ & $37(15.2)$ & $17(7.3)$ \\
\hline Heart failure & $156(14.7)$ & $96(16.4)$ & $43(17.6)$ & $17(7.3)$ \\
\hline Diabetes & $65(6.1)$ & $35(6.0)$ & $18(7.4)$ & $12(5.2)$ \\
\hline $\begin{array}{l}\text { Diuretics before myocardial } \\
\text { infarction }\end{array}$ & $616(58.0)$ & $362(61.8)$ & $166(68.0)$ & $88(37.8)$ \\
\hline \multicolumn{5}{|l|}{ Frequency of exacerbation: } \\
\hline Infrequent & $952(89.6)$ & $501(85.5)$ & $226(92.6)$ & $225(96.6)$ \\
\hline Frequent & $111(10.4)$ & $85(14.5)$ & $18(7.4)$ & $8(3.4)$ \\
\hline \multicolumn{5}{|l|}{ MRC breathlessness score $(n=429)$ : } \\
\hline 1 & $62(14.5)$ & $26(11.7)$ & $16(16.8)$ & $20(17.9)$ \\
\hline 2 & $150(35.0)$ & $75(33.8)$ & $34(35.8)$ & $41(36.6)$ \\
\hline 3 & $114(26.6)$ & $54(24.3)$ & $27(28.4)$ & $33(29.5)$ \\
\hline 4 & $78(18.2)$ & $47(21.2)$ & $14(14.7)$ & $17(15.2)$ \\
\hline 5 & $25(5.8)$ & $20(9.0)$ & $4(4.2)$ & $1(0.9)$ \\
\hline \multicolumn{5}{|l|}{ Type of myocardial infarction: } \\
\hline NSTEMI & $636(59.8)$ & $389(66.4)$ & $157(64.3)$ & $90(38.6)$ \\
\hline STEMI & $427(40.2)$ & $197(33.6)$ & $87(35.6)$ & $143(61.4)$ \\
\hline \multicolumn{5}{|l|}{ GOLD staging $(n=600)$ : } \\
\hline 1 & $103(17.2)$ & $65(16.3)$ & $12(31.6)$ & $26(15.9)$ \\
\hline 2 & $271(45.2)$ & $173(43.5)$ & $16(42.1)$ & $82(50.0)$ \\
\hline 3 & $168(28.0)$ & $121(30.4)$ & $6(15.8)$ & $41(25.0)$ \\
\hline 4 & $58(9.7)$ & $39(9.8)$ & $4(10.5)$ & $15(9.2)$ \\
\hline
\end{tabular}

STEMI=ST elevation MI; NSTEMI=non-ST elevation MI. 
Table 2/ Chronic obstructive pulmonary disease (COPD) and cardiac drugs prescribed before myocardial infarction (MI) in 1063 patients with COPD. Figures are numbers (percentage) of patients according to use of $\beta$ blockers

\begin{tabular}{|c|c|c|c|c|}
\hline & Total & $\begin{array}{l}\text { Never took } \beta \text { blocker }(n=586 \text {, } \\
55.1 \%)\end{array}$ & $\begin{array}{c}\text { Took } \beta \text { blocker before MI } \\
(n=244,23.0 \%)\end{array}$ & $\begin{array}{l}\text { Prescribed } \beta \text { blocker only at MI } \\
\qquad(\mathrm{n}=233,21.9 \%)\end{array}$ \\
\hline $\begin{array}{l}\text { Short acting } \beta \text { agonist or short acting muscarinic } \\
\text { antagonist only }\end{array}$ & $126(11.9)$ & $77(13.1)$ & $28(11.5)$ & $21(9.0)$ \\
\hline $\begin{array}{l}\text { Long acting } \beta \text { agonist or long acting muscarinic } \\
\text { antagonist only }\end{array}$ & $40(3.8)$ & $25(4.3)$ & $9(3.7)$ & $6(2.6)$ \\
\hline Inhaled corticosteroid in combination with above & $454(42.7)$ & $309(52.7)$ & $78(32.0)$ & $67(28.8)$ \\
\hline Digoxin or amiodarone & $212(19.9)$ & $118(20.1)$ & $63(25.8)$ & $31(13.3)$ \\
\hline Antiplatelet agents $(n=966)$ & $457(47.3)$ & $221(45.1)$ & $166(68.0)$ & $70(30.0)$ \\
\hline Angiotensin converting enzyme inhibitor $(n=966)$ & $418(43.3)$ & $188(38.5)$ & $153(62.7)$ & $77(33.1)$ \\
\hline Statin $(n=966)$ & $355(36.8)$ & $161(32.9)$ & $138(56.6)$ & $56(24.0)$ \\
\hline Nitrates and calcium channel blockers & $602(56.6)$ & $320(54.6)$ & $190(77.9)$ & $92(39.5)$ \\
\hline Diuretics & $616(58.0)$ & $362(61.8)$ & $166(68.0)$ & $88(37.8)$ \\
\hline
\end{tabular}


Table 3| Cardiac drugs prescribed during hospital admission for myocardial infarction (MI) in patients with chronic obstructive pulmonary disease (COPD) according to use of $\beta$ blockers

Total Never took $\beta$ blocker Took $\beta$ blocker before MI Prescribed $\beta$ blocker only at MI

\begin{tabular}{lllll} 
Aspirin & $780(85.1)$ & $382(81.5)$ & $176(81.1)$ & $222(96.1)$ \\
\hline Angiotensin converting enzyme inhibitor & $653(72.9)$ & $303(65.7)$ & $152(73.1)$ & $198(87.2)$ \\
\hline Statin & $765(84.0)$ & $359(77.0)$ & $180(84.1)$ & $226(97.8)$ \\
\hline Clopidogrel & $395(70.4)$ & $181(64.0)$ & $105(71.9)$ & $109(82.6)$ \\
\hline
\end{tabular}


Table 4| Model building table showing hazard ratio for mortality in patients with COPD prescribed $\beta$ blocker before myocardial infarction (MI) or during hospital admission for myocardial infarction compared with those never prescribed $\beta$ blocker, adding explanatory variables cumulatively to model. In all cases reference category is "never taking a $\beta$ blocker"

HR $(95 \% \mathrm{Cl})$

Variable added to model in addition to age, sex, and smoking history $\beta$ blocker before MI $\beta$ blocker initiated at MI

\begin{tabular}{|c|c|c|}
\hline +Family history & $0.72(0.57$ to 0.90$)$ & $0.45(0.34$ to 0.60$)$ \\
\hline+ Angina & $0.70(0.56$ to 0.88$)$ & $0.46(0.35$ to 0.61$)$ \\
\hline +Hypertension & 0.69 (0.55 to 0.87$)$ & $0.46(0.35$ to 0.61$)$ \\
\hline +Dyslipidaemia & $0.69(0.55$ to 0.87$)$ & $0.46(0.35$ to 0.61$)$ \\
\hline +Peripheral arterial disease & $0.68(0.54$ to 0.85$)$ & $0.47(0.35$ to 0.62$)$ \\
\hline +Cerebrovascular disease & $0.68(0.54$ to 0.86$)$ & $0.48(0.36$ to 0.63$)$ \\
\hline+ Heart failure & $0.61(0.47$ to 0.81$)$ & $0.43(0.32$ to 0.59$)$ \\
\hline +Diabetes & $0.61(0.46$ to 0.80$)$ & $0.43(0.32$ to 0.59$)$ \\
\hline +Type of MI (STEMI compared with NSTEMI) & $0.62(0.47$ to 0.81$)$ & $0.46(0.34$ to 0.63$)$ \\
\hline +Frequent exacerbations & $0.64(0.48$ to 0.84$)$ & $0.48(0.35$ to 0.66$)$ \\
\hline +Diuretics before MI & $0.64(0.48$ to 0.84$)$ & $0.52(0.38$ to 0.71$)$ \\
\hline+ Anti-arrhythmia drugs & $0.63(0.48$ to 0.83$)$ & $0.52(0.38$ to 0.72$)$ \\
\hline +Angiotensin converting enzyme inhibitor & $0.60(0.45$ to 0.80$)$ & $0.50(0.36$ to 0.69$)$ \\
\hline +Nitrates and calcium channel blockers & $0.59(0.44$ to 0.79$)$ & 0.50 (0.34 to 0.69$)$ \\
\hline+ Anti-platelets & $0.59(0.44$ to 0.79$)$ & $0.50(0.36$ to 0.69$)$ \\
\hline +Statin (fully adjusted model) & $0.59(0.44$ to 0.79$)$ & $0.50(0.36$ to 0.69$)$ \\
\hline
\end{tabular}

STEMI=ST elevation Ml; NSTEMI=non-ST elevation MI. 
Table 5| Causes of death and timing of prescription for $\beta$ blocker in patients with chronic obstructive pulmonary disease (COPD) who had myocardial infarction (MI). Figures are numbers (percentage) of patients according to use of $\beta$ blockers

Cause of death Total Never took $\beta$ blocker $(n=586)$ Took $\beta$ blocker before MI $(n=244)$ Prescribed $\beta$ blocker only at MI $(n=233)$

\begin{tabular}{lllll} 
Cardiac & $220(49.0)$ & $141(64.0)$ & $51(23.2)$ & $28(12.7)$ \\
\hline Non-cardiac & $227(51.0)$ & $153(67.4)$ & $44(19.4)$ & $30(13.2)$ \\
\hline
\end{tabular}


Table 6 | Sensitivity analyses with different methods for analysis and different start times for follow-up in patients with chronic obstructive pulmonary disease (COPD) and myocardial infarction (MI). Figures are hazard ratios for $\beta$ blockers started at admission for MI

\begin{tabular}{|c|c|c|}
\hline Sensitivity analysis undertaken & HR (95\% Cl) & $P$ value \\
\hline Using only diagnoses of COPD before MI instead of before and after & $0.56(0.34$ to 0.93$)$ & 0.03 \\
\hline Adjusted for propensity score as categorical variable in analysis & $0.57(0.43$ to 0.77$)$ & $<0.001$ \\
\hline Matching on propensity score & $0.42(0.28$ to 0.63$)$ & $<0.001$ \\
\hline Adding GOLD stage to model & $0.41(0.26$ to 0.66$)$ & 0.02 \\
\hline Adding infarct severity to model (troponin) & $0.53(0.37$ to 0.74$)$ & $<0.001$ \\
\hline $\begin{array}{l}\text { Repeated analysis splitting patients into only two groups: those taking } \beta \text { blockers or not at discharge from hospital admission for MI } \\
\text { irrespective of use before Ml }\end{array}$ & $0.59(0.37$ to 0.94$)$ & 0.03 \\
\hline Using day of admission +1 as start time of follow-up & $0.54(0.39$ to 0.75$)$ & $<0.001$ \\
\hline Follow-up started from date of discharge & $0.64(0.44$ to 0.94$)$ & 0.02 \\
\hline
\end{tabular}




\section{Figures}

Figure 1: Flow chart showing the patients included and excluded from the analysis identified from MINAP.

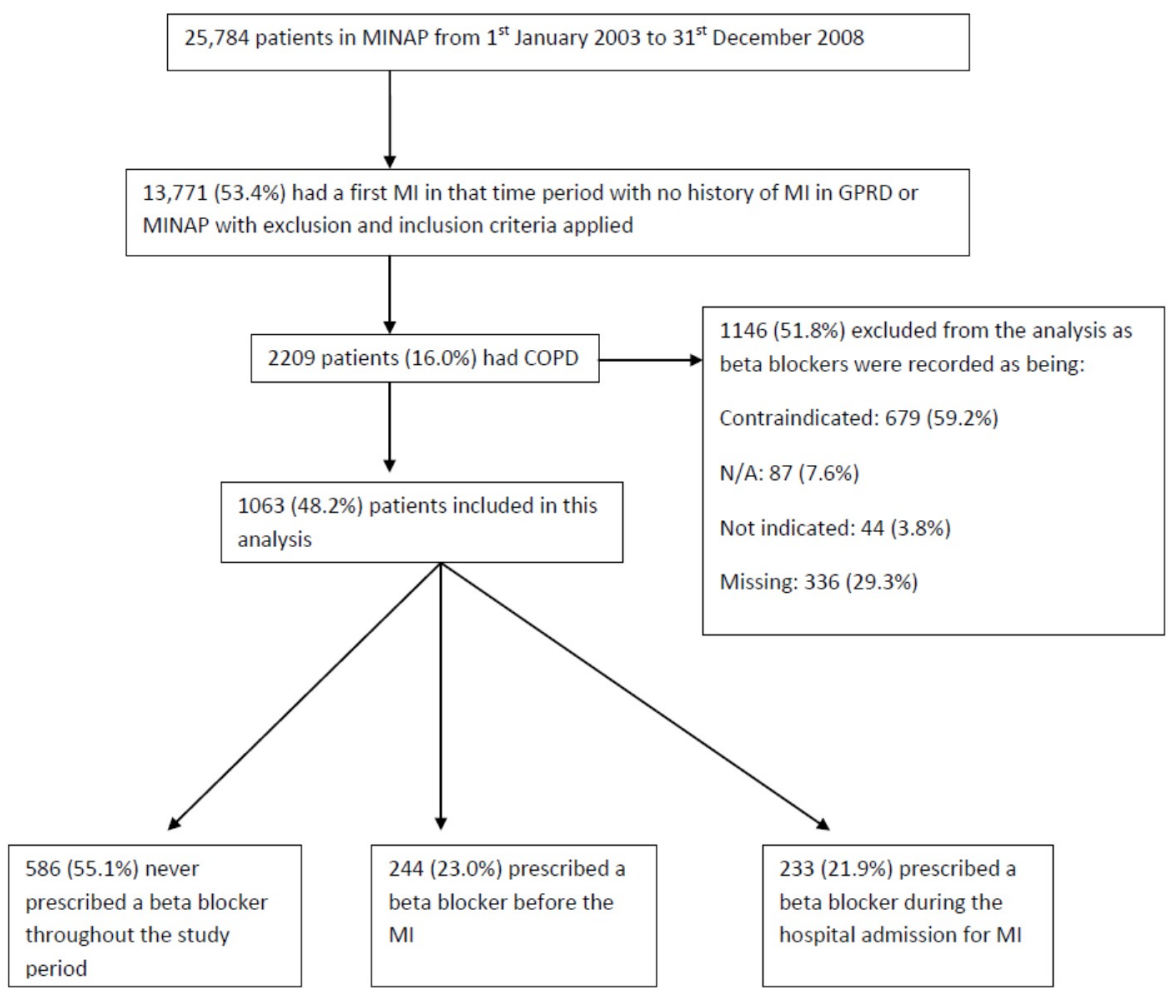

Fig 1 Flow chart showing patients included and excluded from analysis identified from MINAP (Myocardial Ischaemia National Audit Project) 


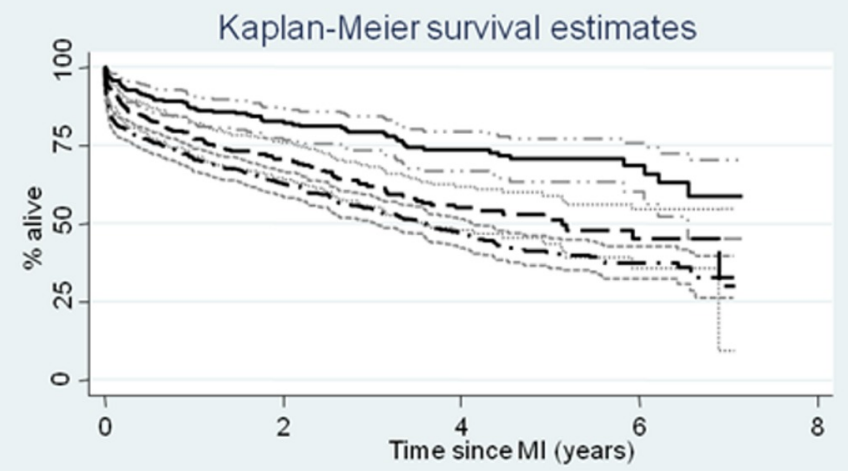

Number at risk never on beta blocker 579 beta blocker pre MI 241 beta blocker post MI 233

\begin{tabular}{|c|c|c|c|}
\hline 303 & 135 & 40 & 0 \\
\hline 140 & 65 & 17 & 0 \\
\hline 158 & 84 & 29 & 0 \\
\hline $\begin{array}{l}95 \% \mathrm{Cl} \\
--- \text { never on bb* }\end{array}$ & $\begin{array}{c}95 \% \mathrm{Cl} \\
--b^{\star} \text { pre Ml }\end{array}$ & & \\
\hline
\end{tabular}

Fig 2 Kaplan-Meier curve showing estimated survival (and 95\% confidence intervals) after myocardial infarction in patients with COPD prescribed $\beta$ blocker before myocardial infarction, during hospital admission for myocardial infarction, or never, excluding deaths on day of diagnosis 